\title{
Comparison of Drug Release From Metoprolol Modified Release Dosage Forms in Single Buffer versus a pH-Gradient Dissolution Test
}

\author{
Sandra Klein ${ }^{1,2}$ and Jennifer B. Dressman ${ }^{1}$
}

\section{M}

Introduction etoprolol is a cardioselective beta blocker that has been classified as a class I substance according to the Biopharmaceutics Classification Scheme BCS [1] meaning that it is highly soluble and highly permeable. The drug is readily and completely absorbed throughout the whole intestinal tract [2-4] but is subject to extensive firstpass metabolism resulting in incomplete bioavailability (about 50\%). After a single oral dose, peak plasma concentrations occur after about 1-2 hours. The drug is eliminated within 3 to 4 hours, which, depending on therapeutic intention, makes it necessary to administer simple formulations of metoprolol up to 4 times daily [5]. Based on these properties and the well-defined relationship between the betablocking effect and plasma drug concentration [6], metoprolol lends itself to an extended-release (ER) formulation. Metoprolol ER formulations smooth out peaks and valleys in the plasma levels and enable less frequent dosing. Dosing intervals are typically reduced to once or twice a day.

Several types of metoprolol ER formulations are available internationally at the time of writing. "Conventional"ER formulations of metoprolol are single-unit, coated dosage forms (tablets) containing metoprolol tartrate, which is highly soluble. These formulations have been the standard medication for hypertension and angina pectoris in Germany for many years. In 1990 Belok-Zok ${ }^{\circledR}$, a different type of ER formulation, was released by AstraZeneca. This formulation consists of a tablet that rapidly disintegrates, releasing micropellets with a diameter of $\sim 0.5 \mathrm{~mm}$ that contain metoprolol succinate. Like the tartrate, metoprolol succinate is highly soluble. Each of the pellets is designed to act as a diffusion cell that delivers the drug at a relatively constant rate, essentially relatively independent of physiological variations within the Gl tract [6].

In 2001 an alternative zero order kinetics (ZOK) formulation was approved for the German market. This consists of a matrix tablet in which metoprolol tartrate is embedded. Hence, to date, there are basically three different types of ER metoprolol formulations available that are registered for equal therapeutic objectives on the German market.

Within the last years, especially in Germany, substitution of innovator products coming off patent by generics has become common practice. However, if substitution is only based on dosage strength without recognizing differences in formulation that could affect rate and/or extent of release, this could place the patient at unnecessary risk.

Based on these considerations, the present study was undertaken to assess the interchangeability of the various ER metoprolol tartrate and succinate dosage forms on the basis of their in vitro dissolution characteristics.

Recent pharmacopoeial test methods for metoprolol ER formulations prescribe the use of USP Apparatus 1 or 2 and simple dissolution media like SGFsp pH 1.2 or phosphate buffer pH 6.8 [7]. Such methods may be useful for quality control purposes in terms of batch-to-batch conformity. However, they do not comprehensively reflect conditions to which a dosage form moving through the human Gl tract will be exposed and therefore cannot be used to predict drug release during the course of $\mathrm{Gl}$ passage. In view of the properties of metoprolol and the release mechanisms of the various formulations on the market, it was deemed both necessary and sufficient to establish a simple $\mathrm{pH}$-gradient method with elements of standard methods such as these described in the USP, but additionally reflecting the changing $\mathrm{pH}$ conditions as the dosage form proceeds through the human Gl tract, in order to predict any differences in in vivo performance.

\section{Materials and methods \\ Materials}

Metoprolol tartrate salt (lot \# 41K1098) standard substance was purchased from SIGMA-Aldrich GmbH, Steinheim, Germany. All other compounds were purchased commercially. The different drug formulations were kindly donated by their manufacturers or purchased commercially. The formulations that were studied are listed in Table 1.

At first glance, it appears that the two categories of "novel" ER formulations are not interchangeable as they contain different amounts of drug. However, these different amounts result from the different molecular weights of the two metoprolol salts (succinate and tartrate). Thus, $95 \mathrm{mg}$ metoprolol succinate corresponds to $100 \mathrm{mg}$ metoprolol tartrate, as both contain $78 \mathrm{mg}$ metoprolol.

\section{Experiments with USP Apparatus 2}

In a first step, drug release was characterized using the paddle apparatus and $900 \mathrm{~mL}$ of SIFsp pH 6.8 as the test medium. A stirring speed of $100 \mathrm{rpm}$ was used to detect 


\section{Table 1: Formulations studied}

\begin{tabular}{|c|c|c|c|}
\hline Brand Name & Manufacturer & Batch & Unit dose (mg) \\
\hline \multicolumn{4}{|c|}{ "Conventional" formulations: coated single unit dosage forms } \\
\hline Azumetop ${ }^{\varpi}$ retard $200 \mathrm{mg}$ & Azupharma & \# 93032 & 200 \\
\hline Meprolol $^{\oplus} 200$ mg Retard & TAD Pharma & \# 2010175 & 200 \\
\hline Metoprolol AL 200 retard & Aliud ${ }^{\oplus}$ Pharma & \# 94803 & 200 \\
\hline Metroprolol-retard ratiopharm ${ }^{\circledR} 200$ & Ratiopharm & \# B 00067 & 200 \\
\hline Meto-Tablinen ${ }^{\circledast}$ retard & Pharmaceutica & \# 54000037 & 200 \\
\hline metodura ${ }^{\oplus}$ retard & MerckDura & \# 72595 A & 200 \\
\hline \multicolumn{4}{|l|}{ "Novel" formulations: multiparticulates } \\
\hline Beloc-Zok ${ }^{\oplus}$ mite & AstraZeneca & \# CM88331A4 & 47.5 \\
\hline Beloc-Zok ${ }^{\odot}$ & AstraZeneca & \# CM9298A3 & 95 \\
\hline Beloc-Zok ${ }^{\circledast}$ forte & AstraZeneca & \# CM1044A1 & 190 \\
\hline \multicolumn{4}{|l|}{ "Novel" formulations: matrix tablets } \\
\hline metodra ${ }^{\oplus} 50$ mg retard & MerckDura & \# 7322A & 50 \\
\hline metodra ${ }^{\oplus} 100$ mg retard & MerckDura & \# 73216A & 100 \\
\hline metodra ${ }^{\oplus} 200$ mg retard & MerckDura & \# 73220A & 200 \\
\hline Metoprolol-ratiopharm ${ }^{\oplus}$ O.K. 100 & Ratiopharm & \# A06404 & 100 \\
\hline Metoprolol-ZK AL 100 retard & Aliud $^{\oplus}$ Pharma & \# 15001 & 100 \\
\hline
\end{tabular}

Table 2: Media and residence times used to simulate gastrointestinal passage in the fasted state

\begin{tabular}{|l|c|c|c|}
\hline Gl section & Passage time & Medium \\
\hline Stomach & $60 \mathrm{~min}$ & SGFsp USP 24 & 1.8 \\
\hline Proximal jejunum & $15 \mathrm{~min}$ & Phosphate buffer Ph. Eur. 1997 & 6.5 \\
\hline Distal jejunum & $15 \mathrm{~min}$ & SIFsp USP 24 & 6.8 \\
\hline Proximal ileum & $30 \mathrm{~min}$ & SIFsp USP 23 & 7.2 \\
\hline Distal ileum & $120 \mathrm{~min}$ & Phosphate buffer & 7.5 \\
\hline Proximal colon & $600(240+360) \mathrm{min}$ & SIFsp USP 24 & 6.5 \\
\hline Distal colon & $600(360+240) \mathrm{min}$ & 6.8 \\
\hline
\end{tabular}

erosion-derived changes in drug release rates that may possibly occur at higher shear rates. Samples $(5 \mathrm{~mL})$ were periodically withdrawn up to 24 hours using a glass syringe. The samples were immediately filtered through a $0.45-\mu \mathrm{m}$ Teflon filter, and the drug concentration was measured with the UV spectrophotometer using a wavelength of $273 \mathrm{~nm}$. All studies were performed in triplicate.

\section{Experiments with USP Apparatus 3}

The first step was to assess apparatus effects on release profiles. The paddle system was compared to USP Apparatus 3 (BioDis ${ }^{\oplus}$ ) by testing release from the dosage forms in SIFsp pH 6.8. Based on observations made during paddle experiments, none of the metoprolol ER formulations included in the present study exhibited a pure erosion- 
controlled drug release. Hence, the instrument parameters were selected on the basis of two series of tests by Rohrs et al. [8] and Klein [9], who described adequate instrument parameters in terms of creating a comparative test system for the in vivo behavior of erosion-diffusion- and diffusioncontrolled MR dosage forms.

Based on the data presented by Rohrs et al. [8] and Klein [9], an agitation rate of 10 dips per minute $(10 \mathrm{dpm})$ was assumed to be capable generating dissolution profiles similar to those obtained with the paddle apparatus at 100 $\mathrm{rpm}$. Both the top and bottom of the glass cylinder were fitted with $420-\mu \mathrm{m}$ mesh screens, and a volume of $220 \mathrm{~mL}$ of test medium was used for all experiments. The test duration was 24 hours in all cases.

In the next step, release profiles were examined using the same instrumental settings but with varying $\mathrm{pH}$ conditions, to check whether drug release might be influenced by changing $\mathrm{pH}$ as the dosage form passes through the $\mathrm{Gl}$ tract. To simulate Gl passage, different compendial media were used (see Table 2). To simulate residence times in the fasted state at different regions of the Gl tract, mean transit times for single unit dosage forms from various gamma scintigraphy studies [10] were used. For colon simulations, in vitro conditions were streamlined to the use of phosphate buffers at $\mathrm{pH} 6.5$ to simulate $\mathrm{pH}$ conditions in the proximal colon and pH 6.8 to simulate more distal sections. Samples $(3 \mathrm{~mL})$ were periodically withdrawn using a plastic syringe. As described for USP 2 experiments, the samples were immediately filtered and analyzed by UV spectrophotometry. All studies were performed in triplicate.

\section{In vitro dissolution profile comparison}

Difference factor $f_{1}$ and similarity factor $f_{2}[11,12]$ were calculated for selected profiles to determine whether a

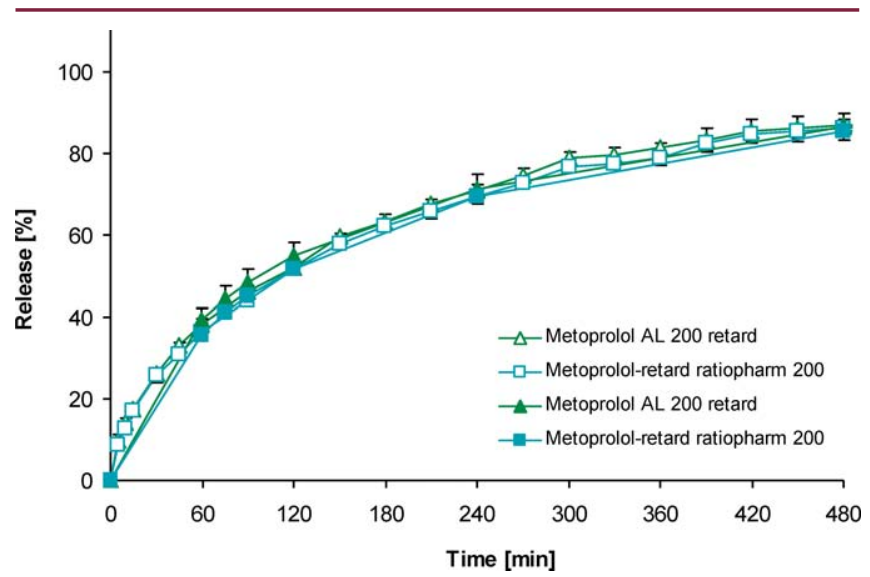

Figure 1. Dissolution profiles of Metoprolol AL 200 retard and Metoprololretard ratiopharm 200 generated with USP Apparatus 2 (open symbols) and USP Apparatus 3 (closed symbols)

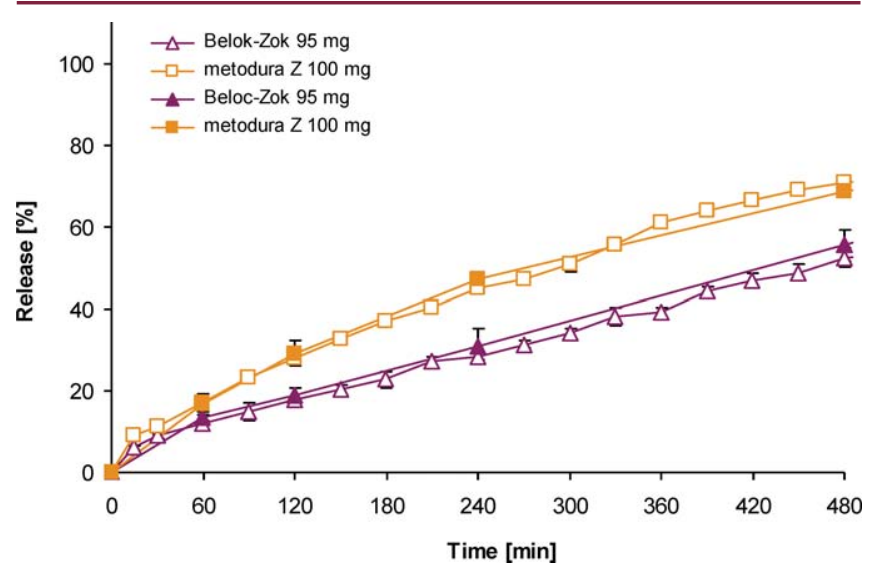

Figure 2. Dissolution profiles of Beloc-Zok $95 \mathrm{mg}$ and metodura Z $100 \mathrm{mg}$ generated with USP Apparatus 2 (open symbols) and USP Apparatus 3 (closed symbols)

paddle speed of $100 \mathrm{rpm}$ corresponds to a reciprocating rate of $10 \mathrm{dpm}$ for both conventional and novel metoprolol ER formulations. Similarity factor $f_{2}$ was calculated for various dissolution profiles to determine whether:

- dissolution profiles of 6 randomized conventional metoprolol ER formulations are similar in a buffer gradient simulating fasted $\mathrm{Gl}$ conditions.

- the dissolution profiles of the "zero-order" multiparticulates of Belok-Zok ${ }^{\oplus}$ are similar to those of the "zero-order" matrices, e.g. metodura ${ }^{\circledR}$.

- the dissolution profiles of conventional metoprolol ER formulations are similar to those of "zero-order" ER formulations, which would indicate that the products are interchangeable in terms of generic substitution.

\section{Results and discussion \\ Comparison of dissolution profiles of USP Apparatus 2 and 3}

Figure 1 illustrates the first 8 hours of the dissolution profiles of two so called "conventional" ER formulations

Table 3: $f_{1}$ and $f_{2}$ values from agitation speed comparison

\begin{tabular}{|c|c|c|}
\hline & $\begin{array}{c}\mathbf{f}_{\mathbf{1}} \\
100 \mathrm{rpm} \text { vs. } 10 \mathrm{dpm}\end{array}$ & $\begin{array}{c}\mathbf{f}_{\mathbf{2}} \\
100 \mathrm{rpm} \text { vs. } 10 \mathrm{dpm}\end{array}$ \\
\hline Beloc-Zok $^{\oplus}$ & $6,12 \%$ & 76,27 \\
\hline $\begin{array}{l}\text { metodura }{ }^{\circledR} Z \\
100 \text { mg retard }\end{array}$ & $2,63 \%$ & 88,61 \\
\hline $\begin{array}{l}\text { Metoprolol AL } \\
200 \text { retard }\end{array}$ & $1,45 \%$ & 89,27 \\
\hline $\begin{array}{l}\text { Metoprolol-retard } \\
\text { ratiopharm } 200\end{array}$ & $7,88 \%$ & 53,39 \\
\hline
\end{tabular}




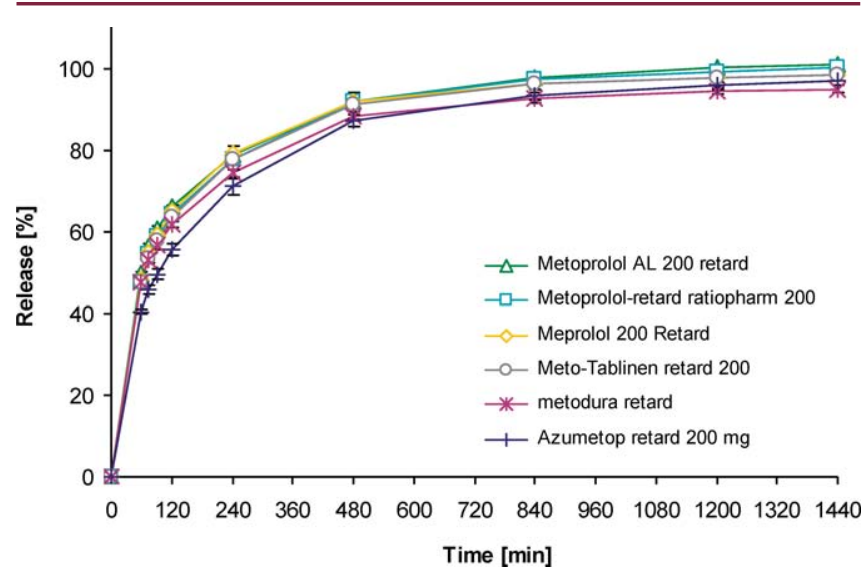

Figure 3. Dissolution profiles of various "conventional" ER formulations of metoprolol using a $\mathrm{pH}$-gradient method

(Metoprolol AL retard and Metoprolol-retard ratiopharm ${ }^{\circledR}$ ) that were generated with both apparatus (Paddle and BioDis ${ }^{\oplus}$ ) using SIFsp pH 6.8 as test medium, and Figure 2 shows those of two "zero order"ER formulations (Belok-Zok ${ }^{\circledR}$ and metodura ${ }^{\circledR}$ ).

Using USP Apparatus 3 with a reciprocating rate of 10 dips per minute (dpm) and 420- $\mu$ m mesh screens at top and bottom of the glass cylinders resulted in dissolution profiles that are very similar to those obtained with the paddle apparatus at $100 \mathrm{rpm}$. This observation was confirmed by calculating $f_{1}$ and $f_{2}$ values. For calculation of both $f_{1}$ and $f_{2}$, mean cumulative percentages released after 60, 120, 240, 480 , and 1440 min were used. Resulting values are given in Table 3.

For all dosage forms tested, $f_{1}$ was less than $10 \%$ and $f_{2}$ was between 50 and 100. Hence, the use of the BioDis ${ }^{\oplus}$ method at $10 \mathrm{dpm} / 420 \mu \mathrm{m} / 420 \mu \mathrm{m} / 220 \mathrm{~mL}$ to investi-

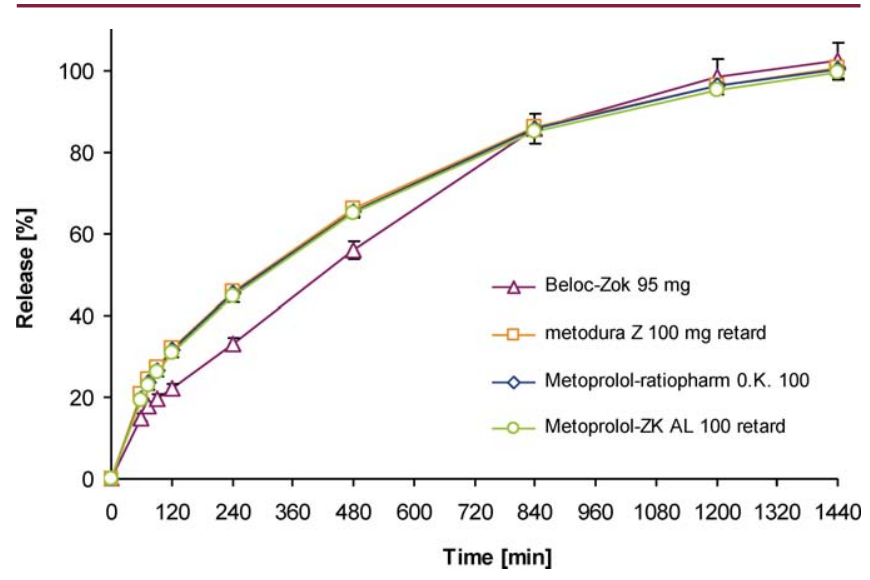

Figure 4. Dissolution profiles of "novel" ER formulations of metoprolol using a pH-gradient method

gate $\mathrm{pH}$ dependency of the formulations using "standard" test conditions could be justified.

Because of the numerous "conventional" Metoprolol ER formulations available on the German/European market, six products from this group were chosen at random and tested using the $\mathrm{pH}$-gradient method (see Figure 3).

All dosage forms showed a drug release that follows firstorder kinetics. The test results show that "conventional" metoprolol ER products exhibit virtually identical dissolution behavior that is independent of $\mathrm{pH}$ and suggest that they are interchangeable. This assumption was supported by a series of tests using SIFsp USP pH 6.8 as the single dissolution medium (data not shown here). To prove similarity of the profiles generated in the $\mathrm{pH}$-gradient, they were compared among one another by $\mathrm{f}_{2}$ calculation using dissolution time points at $60,75,90,120,240$, and $480 \mathrm{~min}$. These time points correspond to FDA criteria, i.e., not more than

\section{Table 4: $f_{2}$ values from comparison of conventional metoprolol ER formulations}

\begin{tabular}{|c|c|c|c|c|c|c|}
\hline & 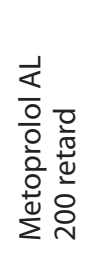 & 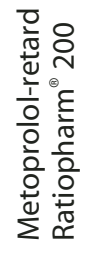 & 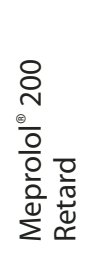 & 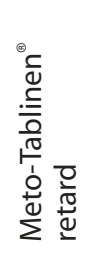 & 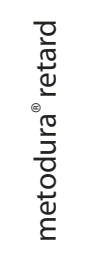 & 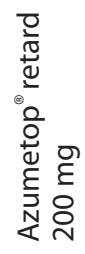 \\
\hline Metoprolol AL 200 retard & & 87.26 & 92.06 & 81.71 & 70.48 & 51.59 \\
\hline Metoprolol-retard ratiopharm ${ }^{\circledast} 200$ & 87.26 & & 95.82 & 95.81 & 77.72 & 55.23 \\
\hline Meprolol $^{\circledR} 200$ Retard & 92.06 & 95.82 & & 90.53 & 74.04 & 53.71 \\
\hline Meto-Tablinen ${ }^{\oplus}$ retard & 81.71 & 95.81 & 90.53 & & 81.28 & 56.94 \\
\hline metodura ${ }^{\oplus}$ retard & 70.48 & 77.72 & 74.04 & 81.28 & & 61.59 \\
\hline Azumetop ${ }^{\oplus}$ retard $200 \mathrm{mg}$ & 51.59 & 55.23 & 53.71 & 56.94 & 61.59 & \\
\hline
\end{tabular}




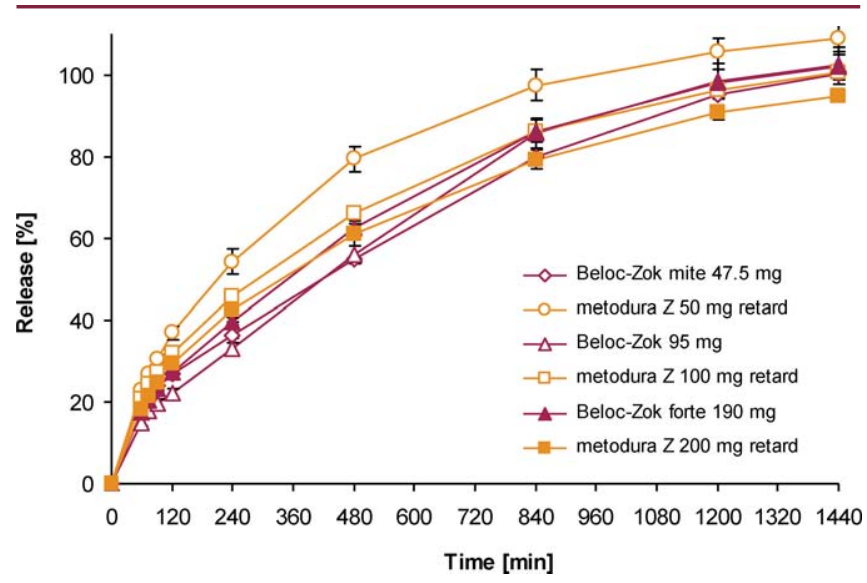

Figure 5: Dissolution profiles of different dosage strengths of "novel" ER formulations of metoprolol using a $\mathrm{pH}$-gradient method

one measurement after $85 \%$ dissolution of the product was considered [13].

All $\mathrm{f}_{2}$ factors calculated are in the range of 50 to 100 (see

Table 4). Therefore, it can be assumed that the conventional ER dosage forms of metoprolol are interchangeable when administered in the fasted state.

In the second step, the dissolution behavior of the "zeroorder"ER formulations was examined (see Figure 4).

Figure 4 shows the release behavior of Beloc-Zok ${ }^{\oplus}$, a once daily tablet consisting of ethylcellulose-coated metoprolol succinate micropellets, and three randomized products of "novel"swellable matrix-type tablets containing metoprolol tartrate. According to the specifications, all four dosage forms should exhibit zero-order drug release. This requirement was not fulfilled under the $\mathrm{pH}$-gradient test conditions. However, it was obvious that the release profiles of the three matrix formulations were superimposable. As all tested matrix formulations consist of the same excipients, have the same shape, and exhibit superimposable dissolution profiles, it was concluded that they are likely from the same manufacturer even though they appear on the market under different brand names.

As for the "conventional" metoprolol ER formulations, drug

Table 5: $f_{2}$ values from comparison of different strengths of Beloc-Zok ${ }^{\circledR}$

\begin{tabular}{|llll|}
\hline & & & $\mathrm{f}_{2}$ \\
\hline $\begin{array}{l}\text { Belok-Zok }^{\circledast} \\
\text { mite } 47.5 \mathrm{mg}\end{array}$ & versus & $\begin{array}{l}\text { Belok-Zok } \\
\text { mite 95 } \mathrm{mg}\end{array}$ & 70.17 \\
\hline $\begin{array}{l}\text { Belok-Zok } \\
\text { mite 47.5 mg }\end{array}$ & versus & $\begin{array}{l}\text { Belok-Zok } \\
\text { forte 190 mg }\end{array}$ & 70.65 \\
\hline $\begin{array}{l}\text { Belok-Zok } \\
\text { mite 95 mg }\end{array}$ & versus & $\begin{array}{l}\text { Belok-Zok } \\
\text { forte 190 mg }\end{array}$ & 69.77 \\
\hline
\end{tabular}

Table 6: $f_{2}$ values from comparison of different strengths of metoduara ${ }^{\circledR} Z$

\begin{tabular}{|c|c|c|c|}
\hline & & & $f_{2}$ \\
\hline $\begin{array}{l}\text { metodura } \mathrm{Z} 50 \\
\text { mg retard }\end{array}$ & versus & $\begin{array}{l}\text { metodura } Z \\
100 \mathrm{mg} \text { retard }\end{array}$ & 54.50 \\
\hline $\begin{array}{l}\text { metodura }{ }^{\oplus} \mathrm{Z} 50 \\
\text { mg retard }\end{array}$ & versus & $\begin{array}{l}\text { metodura }{ }^{\oplus} \\
200 \text { mg retard }\end{array}$ & 45.28 \\
\hline $\begin{array}{l}\text { metodura }{ }^{\oplus} \\
100 \text { mg retard }\end{array}$ & versus & $\begin{array}{l}\text { metodura }^{\oplus} Z \\
200 \text { mg retard }\end{array}$ & 67.10 \\
\hline
\end{tabular}

release from "novel" ER formulations was independent of $\mathrm{pH}$. A series of tests using SIFsp USP pH 6.8 as dissolution medium (data not shown here) resulted in dissolution profiles comparable to those with the $\mathrm{pH}$-gradient method.

Whereas"conventional"ER formulations are available only in a strength of $200 \mathrm{mg}$ metoprolol tartrate per tablet, three different strengths exist for both types of "novel" formulations. The objective of the third and final step of this series of tests was to examine whether there are dose-dependent changes in the dissolution profile of the "novel" formulations. Additional experiments were performed using the $\mathrm{pH}$ gradient method. Six different dosage forms were included in this study:Belok-Zok ${ }^{\oplus}$ multiparticulates at three strengths $(47.5,95,190 \mathrm{mg})$ and the corresponding strengths of metodura $\mathrm{Z}(50,100,200 \mathrm{mg}$ ) tablets (see Figure 5).

In previous experiments (data not shown here), it was shown that drug release is not $\mathrm{pH}$-dependent from conventional products containing $200 \mathrm{mg}$ or from novel products containing $100 \mathrm{mg}$ metoprolol salt. Percentage release vs. time profiles from the Beloc-Zok ${ }^{\circledR}$ proved to be almost independent of strength of the dosage from. This observation was confirmed by calculating $\mathrm{f}_{2}$ values for the complete dissolution profile (60-1440 $\mathrm{min}$ ). Values of $\mathrm{f}_{2}$ are given in Table 5.

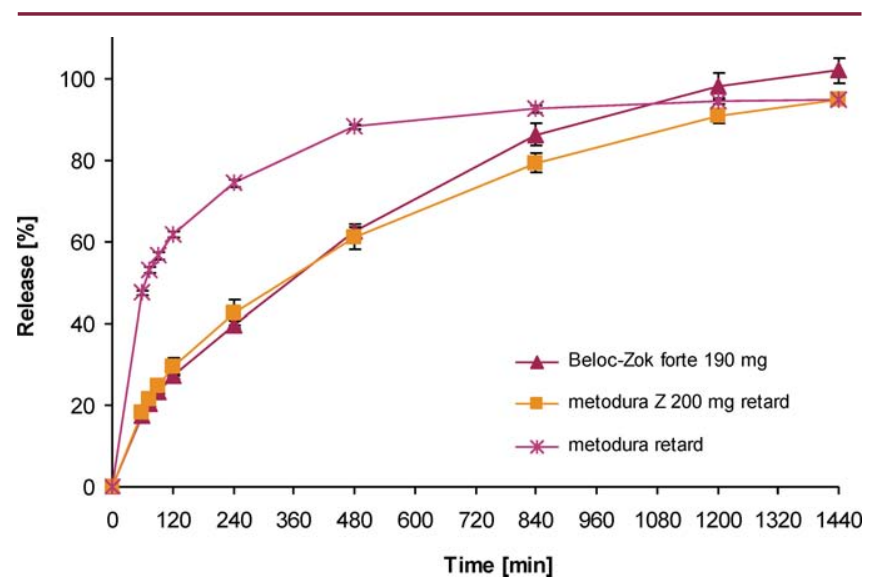

Figure 6: Comparison of drug release from different types of metoprolol ER formulations 
Table 7: $f_{2}$ values from comparison of conventional and novel types of metoprolol ER formulations

\begin{tabular}{|c|c|c|c|}
\hline & & & $f_{2}$ \\
\hline $\begin{array}{l}\text { Belok-Zok }{ }^{\circledR} \text { forte } \\
190 \mathrm{mg}\end{array}$ & versus & $\begin{array}{l}\text { metodura }{ }^{\oplus} \\
200 \text { mg retard }\end{array}$ & 67.47 \\
\hline $\begin{array}{l}\text { Belok-Zok }{ }^{\circledR} \text { forte } \\
190 \text { mg }\end{array}$ & versus & $\begin{array}{l}\text { metodura } \\
\text { retard }\end{array}$ & 28.97 \\
\hline $\begin{array}{l}\text { metodura } Z \\
200 \text { mg retard }\end{array}$ & versus & $\begin{array}{l}\text { metodura } \\
\text { retard }\end{array}$ & 29.68 \\
\hline
\end{tabular}

By contrast, release from the matrix tablet seemed to be dependent on both the shape of the dosage form and the amount of drug dispersed in the matrix. By comparing dissolution profiles of three strengths of metodura ${ }^{\circledR}$, a clear trend can be observed with drug release rate (expressed as $\%$ label strength) increasing from higher to lower strengths (see Figure 5). As the appearance of the 50-mg tablet differs from that of the 100- and 200-mg tablets and drug release rate is particularly high for this tablet, it seems that the geometry of the matrix formulation is likely to be the culprit. To check for similarity of the dissolution profiles of metodura $Z_{1} f_{2}$ was additionally calculated using all sampling time points of the dissolution profile (60-1440 min).

$\mathrm{F}_{2}$ values in Table 6 clearly indicate that drug release rate from metodura $Z$ retard differs among the strengths. Dissolution profiles from the lowest and highest dose are different $\left(f_{2}<50\right)$ so they cannot be considered interchangeable (i.e., 4 metodura ${ }^{\oplus} Z 50 \mathrm{mg}$ retard would not have the same profile as 1 metodura ${ }^{\circledR} 200$ mg retard).

In terms of assessing the interchangeability of the different types of metoprolol dosage forms, dissolution profiles of three formulations, representing the different types of formulations currently available on the market, were compared using dissolution data generated with the $\mathrm{pH}$-gradient method (see Figure 6). A dosage strength of $190 / 200 \mathrm{mg}$ had to be used for this comparison as "conventional"formulations are available only in this strength.

Overall, dissolution results indicate that "conventional"

Table 8: $f_{2}$ values from comparison of "zero-order" multiparticulates and matrices of same strength

\begin{tabular}{|cccc|}
\hline & & $\mathrm{f}_{2}$ \\
\hline $\begin{array}{c}\text { Belock-Zok } \\
\text { mite } 47.5 \mathrm{mg}\end{array}$ & versus & $\begin{array}{c}\text { metodura }{ }^{\circledR} \mathrm{Z} 50 \\
\text { mg retard }\end{array}$ & 43.51 \\
\hline $\begin{array}{c}\text { Belock-Zok } \\
95 \mathrm{mg}\end{array}$ & versus & $\begin{array}{c}\text { metodura }{ }^{\circledR} \mathrm{Z} 100 \\
\text { mg retard }\end{array}$ & 56.05 \\
\hline $\begin{array}{c}\text { Belock-Zok } \\
\text { forte } 190 \mathrm{mg}^{\circledR}\end{array}$ & versus & $\begin{array}{c}\text { metodura }{ }^{\circledR} \mathrm{Z} 200 \\
\text { mg retard }\end{array}$ & 67.47 \\
\hline
\end{tabular}

and "novel"ER formulations of metoprolol are not therapeutically interchangeable. $F_{2}$ was calculated using dissolution time points at $60,75,90,120,240,480,840,1200$, and 1440 min. The values are given in Table 7.

According to the specifications, both dosage forms BelokZok $^{\oplus}$ and metodura ${ }^{\oplus}$ Z should exhibit zero-order drug release. This requirement was not fulfilled under the $\mathrm{pH}-$ gradient test conditions. Despite different release mechanisms and different salts within the formulations, no significant difference in the dissolution profiles was detected between the 190-mg and 200-mg "zero-order" dosage forms, but this observation cannot be generalized to other strengths (see Table 8).

It was confirmed by $\mathrm{f}_{2}$ calculation (see Table 8 ) that the 95/100- and 190/200-mg dosage forms resulted in similar dissolution profiles. However, the 47.5-mg and 50-mg dosage forms show particularly large deviations, so that substitution of these two formulations for one another is questionable.

From these results, it is obvious that "conventional" and "novel"ER formulations cannot be considered therapeutically interchangeable. Substitution between these two product types should be avoided, since this could result in an increased risk of side effects on the one hand (ZOK $\leftleftarrows$ conventional) or a reduction of the therapeutic effect on the other hand (conventional Æ ZOK). Nevertheless, all but Belok-Zok ${ }^{\oplus}$ can be substituted for one another under the current German "aut idem" rule, even though switching between "conventional" and "zero-order" is expected to result in quite different release profiles in vivo.

\section{Summary}

Results of these studies indicate that the USP Apparatus 3 $\mathrm{pH}$-gradient method is a convenient and discriminating method for comparing the drug release behavior of ER dosage forms during their passage through the GI tract. In the present study, it could be shown that it is possible to differentiate between individual release characteristics of metoprolol ER dosage forms. Specificity of drug release profiles during gastrointestinal passage as well as $\mathrm{pH}$ dependency of drug release could be shown. The method used in the present study therefore represents a useful tool in estimating the interchangeability of seemingly similar dosage forms when administered in the fasted state.

\section{References}

1. Guidance for Industry: Waiver of in vivo bioavailability and bioequivalence studies for immediate-release solid oral dosage forms based on a biopharmaceutics classification system. U.S. Department of Health and Human Services, Food and Drug Administration, Center for Drug Evaluation and Research (CDER): Rockville, MD, 2000. 
2. Jobin, G., et al. Investigation of drug absorption from the gastrointestinal tract of man. I. Metoprolol in the stomach, duodenum and jejunum. Br.J. Clin.

Pharmacol. 1985, 19 (Suppl. 2), 97S-105S.

3. Vidon, N., et al. Investigation of drug absorption from the gastrointestinal tract of man. II. Metoprolol in the jejunum and ileum. Br.J. Clin. Pharmacol. 1985, 19 (Suppl. 2), 107S-112S.

4. Godbillon, J., et al. Investigation of drug absorption from the gastrointestinal tract of man. III. Metoprolol in the colon. Br.J. Clin. Pharmacol. 1985, 19 (Suppl. 2), 113S-118S.

5. Sweetman, S. C., Ed. Martindale: The Complete Drug Reference, 33rd ed.; Pharmaceutical Press: London, England, 2002.

6. Kendall, M.J., et al. Controlled release metoprolol. Clinical pharmacokinetic and therapeutic implications. Clin. Pharmacokinet. 1991, 21 (5), 319-330.

7. United States Pharmacopeia and National Formulary USP 26-NF 21. The United States Pharmacopeial Convention, Inc.: Rockville, MD, 2003.

8. Rohrs, B.R., et al. USP Dissolution Apparatus 3 (Reciprocating Cylinder): Instrument Parameter Effects on Drug release from Sustained Release Formulations. J. Pharm. Sci. 1995, 84 (8), 922-926.
9. Klein, S. Evolution of BioDis ${ }^{\oplus}$ methodology: selection of adequate instrument parameters. In Biorelevant Dissolution Test Methods for Modified Release Dosage Forms. Doctoral Thesis, Institute of Pharmaceutical Technology, Johann Wolfgang Goethe University Frankfurt, Shaker-Verlag: Aachen/Germany, 2005; ISBN 3-8322-4276-7; pp 117-127.

10. Davis, S. S.; Hardy, J. G.; Fara, J. W. Transit of pharmaceutical dosage forms through the small intestine. Gut 1986, $27(8), 886-892$.

11. Moore, J. W.; Flanner, H. H. Mathematical comparison of dissolution profiles. Pharm. Technol. 1996, 20, 64-74.

12. Shah, V. P., et al. Dissolution profile comparison using similarity factor, f2. Dissolution Technologies 1999, $6(3), 21$.

13. Guidance for Industry: SUPAC-MR: Modified Release solid oral dosage forms, in Scale-up and post approval changes: chemistry, manufacturing, and controls; in vitro dissolution testing and in vivo bioequivalence documentation. U.S. Department of Health and Human Services, Food and Drug Administration, Center for Drug Evaluation and Research (CDER): Rockville, MD, 1997. 